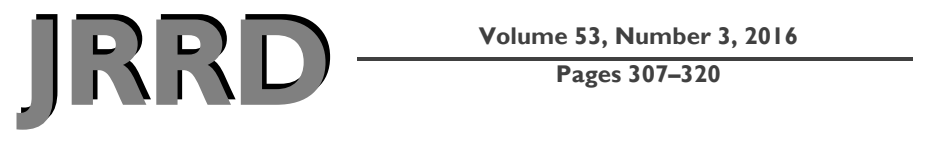

\title{
Enhanced vocational rehabilitation for Veterans with mild traumatic brain injury and mental illness: Pilot study
}

\author{
Maureen K. O’Connor, PsyD; ${ }^{1-2 *}$ Lisa Mueller, PhD; ${ }^{1}$ Eunice Kwon, PhD; ${ }^{1}$ Charles E. Drebing, PhD; ${ }^{1}$ Ashley \\ A. O’Connor, MSW; ${ }^{1}$ Alicia Semiatin, PsyD; ${ }^{1}$ Shihwe Wang, PhD; ${ }^{1}$ Ryan Daley, BA ${ }^{\mathbf{1}}$ \\ ${ }^{1}$ Veterans Integrated Service Network 1 Mental Illness Research, Education, and Clinical Center, Department of Psy- \\ chology, Bedford Department of Veterans Affairs Medical Center, Bedford, MA; ${ }^{2}$ Boston University School of Medi- \\ cine, Boston, MA
}

\begin{abstract}
Work plays a significant role in how people identify themselves, and successful return to work is associated with significant psychological and rehabilitative benefits. Unfortunately, despite the many benefits of employment, Veterans who experience mild traumatic brain injury and have mental health issues often have significant difficulty getting their vocational needs met. Considering that a consistent relationship between cognitive dysfunction and difficulties with employability has been firmly established, cognitive rehabilitation may enhance engagement in vocational rehabilitation and return to work outcomes. In this pilot study, we evaluated a 12 wk cognitive rehabilitation intervention embedded within vocational rehabilitation services. Eighteen Veterans were randomly assigned to receive either the embedded cognitive rehabilitation intervention $(n=10)$ or a control condition offering supportive client-centered therapy that did not focus on employment or cognitive rehabilitation $(n=8)$; all Veterans (intervention and control groups) received vocational rehabilitation services. This pilot feasibility study demonstrated efficient implementation of an embedded cognitive rehabilitation intervention within vocational rehabilitation. The current pilot data revealed small to moderate effect sizes on employment outcomes. Given these preliminary findings, a larger outcome study is warranted.
\end{abstract}

Key words: cognitive rehabilitation, compensated work therapy, competitive employment, mental illness, mild traumatic brain injury, OIF/OEF, supported employment, Veterans, vocational rehabilitation, transitional work experience.

\section{INTRODUCTION}

Most individuals with mild traumatic brain injury (mTBI) experience some acute changes in cognition that fully resolve within the first 3 mo postinjury [1-3]. A small minority of individuals have persistent cognitive and functional complaints [4-7], such as difficulties with concentration and memory, that are nonspecific and are also frequently found in those with mental illness (MI) who have never experienced an mTBI. The comorbid occurrence of mTBI and MI is high among the Veteran population [8-11]. Mental health diagnoses in these populations often better account for lingering cognitive symptoms than the mTBI itself [12-13], consistent with the civilian literature on mTBI [14-18]. In fact, in a sample of more than 4,000 Army Veterans with a psychiatric

\footnotetext{
Abbreviations: ISI = Instructional Systems Inc, $\mathrm{MI}=$ mental illness, $\mathrm{mTBI}=$ mild TBI, OIF $/ \mathrm{OEF}=$ Operation Iraqi Freedom/Operation Enduring Freedom, PTSD = posttraumatic stress disorder, $\mathrm{SD}=$ standard deviation, $\mathrm{SE}=$ supported employment, $\mathrm{TBI}=$ traumatic brain injury, $\mathrm{TWE}=$ transitional work experience, VA = Department of Veterans Affairs.

*Address all correspondence to Maureen K. O'Connor, PsyD; 200 Springs Rd (116B), Bedford, MA 01730; 781687-2830; fax: 781-687-3224.

Email: maureen.oconnor@va.gov

http://dx.doi.org/10.1682/JRRD.2014.10.0231
} 
diagnosis, such as depression, generalized anxiety disorder, or posttraumatic stress disorder (PTSD) and no history of mTBI, the incidence of postconcussive syndrome symptoms, including cognitive difficulties, was greater than it was for Veterans with a history of mTBI [19]. Veterans with cognitive impairment are at significantly greater risk for poor employment outcomes [10], and moderate cognitive impairment has been associated with poor engagement in vocational rehabilitation in a Veteran sample [20].

Unfortunately, despite the many benefits of employment, Veterans and civilians who experience mTBI and/ or have MI often have significant difficulty getting their vocational needs met [10,21-24]. Work plays a significant role in how people identify themselves and how they are described by their families, communities, and society. Successful employment fosters financial independence while promoting engagement in social relationships and enhancing emotional well-being [25-26]. Successful return to work is associated with significant psychological and rehabilitative benefits, including improved mental health [27-28], opportunities to enhance self-esteem [29-30], and better quality of life [31-33].

Vocational rehabilitation, established to help World War I Veterans return to gainful employment, has since developed into therapeutic models to assist any individual with a disability or disorder return to work [34]. Supported employment (SE) and transitional work experience (TWE) are two such models. SE, as conceptualized by Becker and Drake, was developed specifically to help adults with psychiatric disabilities obtain and maintain competitive employment [35]. SE emphasizes engaging an individual in competitive work and then providing the training and support required to remain employed in the specific work setting or the "place then train” approach [36-37]. In TWE programs, temporary jobs are provided for the Veteran on a time-limited basis while staff assist the Veteran to address issues that hinder competitive employment (lack of job search skills, interpersonal skill development, etc.) and provide assistance with the competitive job search [21,38]. SE and TWE are national Department of Veterans Affairs (VA) vocational rehabilitation models that share the goal of helping Veterans overcome barriers to successful return to competitive employment. Both programs work with Veterans on an individual basis, tailoring services and support to meet each Veteran's unique needs. The current study focused on Veterans in VA vocational rehabilitation, including both SE and TWE.

Despite the promise and availability of vocational rehabilitation for Veterans, not all individuals benefit, with many dropping out or being unable to obtain and retain competitive employment over the course of a year $[21,31,39]$. These findings suggest that efforts to enhance the outcome of vocational services for Veterans are needed. Considering that a consistent relationship between cognitive dysfunction and difficulties with employability has been firmly established [40-42], cognitive rehabilitation may enhance engagement in vocational rehabilitation and return to work outcomes. Of the studies that have been conducted, results are promising. For example, findings from two nonrandomized studies suggest that including cognitive rehabilitation in traditional vocational rehabilitation improved return to work outcomes for civilians with traumatic brain injury (TBI) [43-44]. McGurk et al. conducted a randomized controlled trial comparing a multicomponent cognitive retraining program with traditional SE to traditional SE alone and found that work outcomes were better for those civilians with serious MI in the enhanced model [22]. Recently Twamley et al. investigated the effect of a 12 wk cognitive rehabilitation program in Operation Iraqi Freedom/Operation Enduring Freedom (OIF/OEF) Veterans with mTBI to moderate TBI that were enrolled in SE [45]. The majority of enrolled Veterans also met criteria for PTSD. There was no report of additional mental health diagnoses. Findings revealed significant reductions in self-reported postconcussive symptoms and prospective memory function for the intervention group compared with the control group. Small to medium effect sizes were found for PTSD symptom severity and depression severity. Small to medium effect sizes were also found for attainment of competitive employment within 14 wk. These results demonstrate the positive effect of cognitive rehabilitation in OIF/OEF Veterans with cognitive impairments caused by TBI and PTSD who are engaged in vocational rehabilitation.

The current study sought to add to the small body of literature suggesting that Veterans with cognitive impairment and employment goals may benefit from the addition of cognitive rehabilitation services to traditional vocational rehabilitation services. The current study is unique in several ways. The study expands on the findings of Twamley et al. by broadening the target population to Veterans from all eras of service with reported 
mTBI and specifically including Veterans with comorbid multiple mental health issues [45]. The program is also designed as an embedded cognitive rehabilitation program within the VA vocational rehabilitation programs in two ways: (1) all cognitive rehabilitation materials were specific to return to work goals and (2) vocational rehabilitation specialists participated in the program, meeting with the Veterans and their cognitive rehabilitation specialists at the end of each session to review intervention material taught and discuss application of the material to real-world, work-related goals. Embedding cognitive rehabilitation within vocational rehabilitation is likely to offer benefits over simply adding it as an adjunct to vocational rehabilitation, consistent with the body of literature demonstrating increased effectiveness of integrated mental health and vocational rehabilitation services when compared with traditional brokered service models [23,46-49]. One advantage of embedded services is the improved flow of communication about cognitive function, rehabilitation efforts, and vocational rehabilitation progress that can be used by multiple specialists involved in helping the Veteran meet vocational goals.

We set out to test the feasibility and potential efficacy of adding an embedded $12 \mathrm{wk}$ cognitive rehabilitation intervention to standard vocational rehabilitation in Veterans with histories of mTBI and MI. We hypothesize that the addition of an embedded cognitive rehabilitation intervention will improve employment outcomes above and beyond standard vocational rehabilitation. Feasibility goals were to determine (1) whether Veterans entering vocational rehabilitation would be interested in cognitive rehabilitation; (2) how many interested Veterans would be eligible, enroll, and be retained; and (3) what qualitative (challenges, satisfaction, Veteran feedback) and quantitative (effect sizes) outcomes would tell us about embedded cognitive rehabilitation intervention effectiveness. Information gathered in this pilot study was intended to inform larger studies.

\section{METHODS}

\section{Participants}

Participants were recruited by flyers and brochures placed around the hospital. In addition, the study was announced during the vocational rehabilitation program orientation. Interested Veterans could contact the research- ers directly or leave their names on a sign-up sheet to be contacted by the researchers.

Inclusion criteria included (1) aged 18 yr or older, (2) history of mTBI as defined by the American Congress of Rehabilitation Medicine guidelines [50], (3) diagnosis of an MI co-occurring with mTBI as corroborated between the Structured Clinical Interview for Diagnostic and Statistical Manual of Mental Disorders-4th Edition Mood and Anxiety subsections administered at baseline and a review of participants' electronic medical record, (4) impairment in cognitive functioning as measured by a decrease of $\geq 1$ standard deviation (SD) below normative mean on any cognitive measure, (5) a "vocational problem" defined as being unemployed or underemployed, (6) potential for return to competitive employment within 6 mo based on history of competitive employment within the last $3 \mathrm{yr}$ and stated goal of returning to competitive employment within $8 \mathrm{mo}$, and (7) enrollment and participation in vocational rehabilitation.

Exclusion criteria included (1) non-English speaker; (2) less than 10 yr of formal education; (3) history of nonTBI neuropsychological disorder resulting in significant cognitive impairment not likely to respond to cognitive rehabilitation (i.e., vascular dementia, Alzheimer disease); (4) cognitive impairment significant enough to prevent the candidate from meaningfully participating in the intervention, as defined by a Mini-Mental State Examination score of <25 [51]; (5) other chronic medical problems that would make it unlikely that the participant will be able to obtain and/or sustain a competitive job in the next $8 \mathrm{mo}$; (6) no intention of staying in the area for $12 \mathrm{mo}$; (7) previous screening for the study; and (8) involvement in prior research studies of vocational rehabilitation or involvement in other research studies that would interfere with participation in the current study.

\section{Description of Intervention and Control Conditions}

In this random assignment clinical trial, all Veteran participants were enrolled in a VA vocational program and assigned to either the embedded cognitive rehabilitation intervention or a control condition. Veterans in the embedded cognitive rehabilitation intervention participated in a 12-session program designed to assist participants in their efforts to return to employment. Participants met individually with a cognitive rehabilitation specialist. Seven intervention participants were seen by a doctorallevel neuropsychology staff and three were seen by master's level trainees. They were taught (1) compensatory 
strategies to help manage cognitive difficulties in the occupational environment and (2) skills to recognize and control unhelpful behaviors at work, deal with negative emotions, and foster positive relationships among coworkers and employers. Veterans and their cognitive rehabilitation specialists met together with the Veterans' vocational rehabilitation specialists to facilitate transfer of training.

Veterans were also given laptop computers containing Instructional Systems Inc (ISI) software (Hackensack, New Jersey) with modules specifically selected to meet the training and rehabilitation needs of Veterans with mTBI and MI. These included work readiness modules that were completed as assigned homework between office sessions and discussed in subsequent sessions. The work readiness modules consisted of the following: (1) You Can Make It Happen, (2) Essay Writing, (3) Reading Series (i.e., Workplace Reading, Developmental Reading, Remedial Reading), (4) Customer Service (i.e., Working with People), and (5) Life Skills. The You Can Make It Happen modules focused on personal growth and goal achievement through specifically outlined steps for success (e.g., creating a vision and identifying necessary steps for achieving the goal). The Essay Writing modules focused on writing journal entries reflecting on life experiences and challenges, while the reading series modules addressed relationship building. The Customer Service modules focused on interpersonal skills development, and the Life Skills modules addressed basic skills needed to function in life and society. Laptop computers also contained Microsoft Office programs (Microsoft Corporation; Redmond, Washington). Table 1 provides the syllabus for the embedded 12 session cognitive rehabilitation intervention.

Veterans in the control group were also seen for 12 sessions of supportive client-centered therapy. Two participants were seen by doctoral-level neuropsychology staff, and three participants were seen by master's level trainees and staff. Veterans in the control group did not receive any specific skills training or guided discussion related to employment. That is, the sessions were not focused on employment or cognitive rehabilitation in order to ensure clear differences for between-group comparisons. Veterans in the control group were encouraged to discuss any topic of current personal interest, relevance, or distress. There was no joint meeting with the vocational rehabilitation specialist. The control group also received laptop computers loaded with the Microsoft Office programs (but not the ISI software).
This VA study required the team to work within Federal government policies to develop the laptop computer security protocol, which included (1) encryption of study laptop computers with VA firewall and security software, (2) institutional installation of the study software off a disc, (3) cleaning of the laptop computer hard drives after each study participant had completed the study. The laptop computer hard drives became property of the VA medical center after the study.

\section{Data Analysis}

\section{Qualitative}

Consistent with our stated goal of evaluating the intervention for Veteran challenges, satisfaction, and feedback, all Veterans in the intervention condition completed a satisfaction interview at the end of the embedded cognitive rehabilitation intervention (3-4 mo postbaseline). Questions included (1) Veterans' ratings of usefulness and satisfaction with the sessions and ISI software, (2) the specific topics they found most and least useful to their goals, (3) any general positive and negative feedback, and (4) recommendations for future versions of the intervention.

\section{Quantitative}

Although the results of this pilot study are described by statistical analyses later, we were primarily interested in obtaining an estimate of effect size, as would be appropriate at the current feasibility level of analysis. Importantly, these analyses are intended to prepare for a fully powered randomized clinical trial and were not intended to capture statistically significant differences between the groups. Employment outcomes were collected over the $1 \mathrm{yr}$ period for several analyses. All continuous measures were examined to determine whether parametric assumptions were met. Finding that parametric assumptions were not met for all of our continuous variables, we used nonparametric tests (Mann-Whitney $U$ ). Chi-square tests were used to analyze categorical variables. The $d$ effect size was calculated for all relevant findings. In addition, it is also important to note that at this most preliminary stage of investigation we decided to focus our analyses on individuals who did not withdraw from the study, so we did not use an intent to treat approach. 
Table 1.

Enhanced vocational rehabilitation program outline.

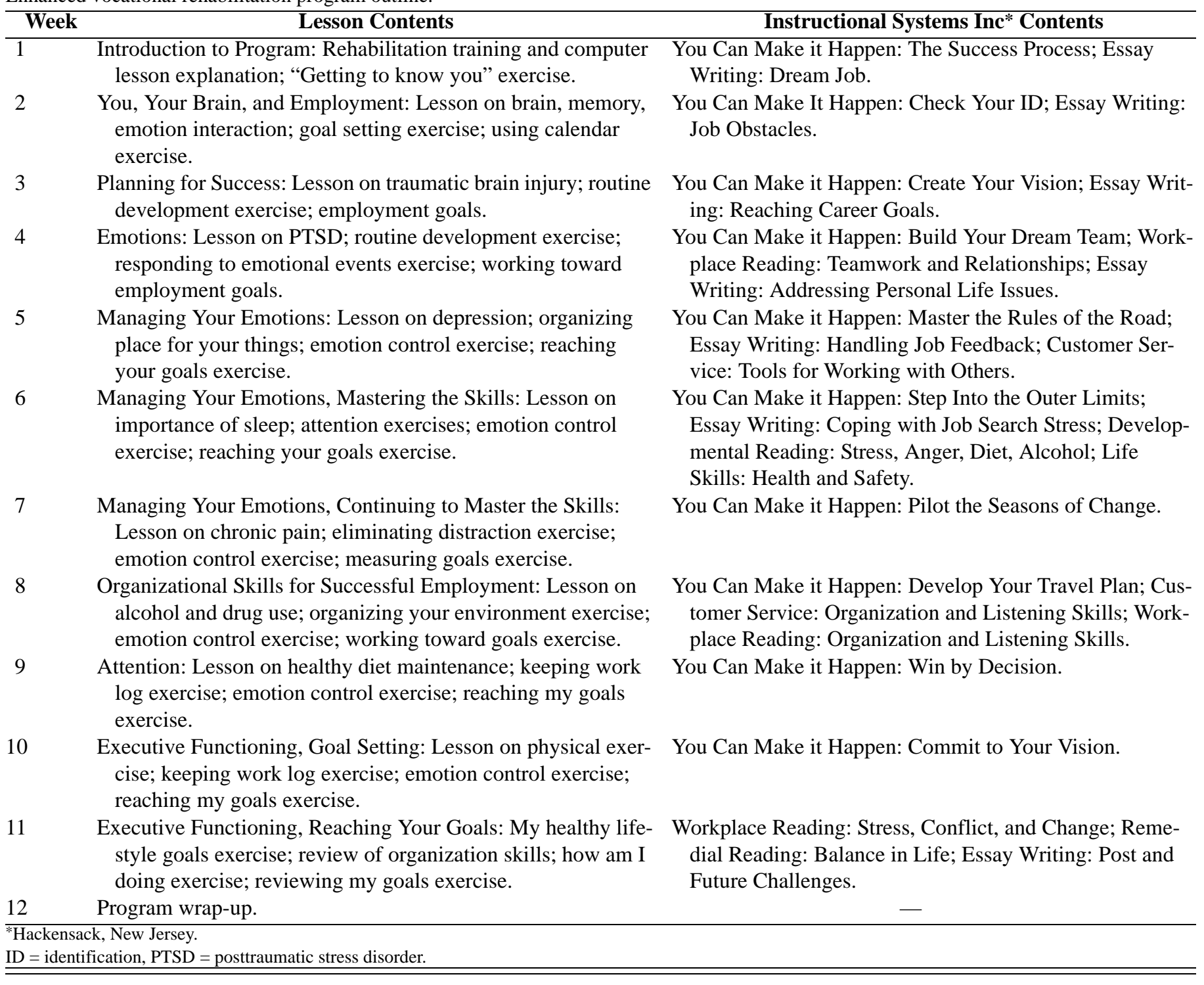

\section{Definitions of Outcome Variables}

The main outcome variable of interest for this pilot was employment. However, employment can be defined in several ways, including working as an employee for someone else, working for oneself, and day labor in which work is exchanged for pay but there is no official employee and employer relationship (or even contractor and vendor relationship). Thus, outcomes were examined with respect to any work for pay including as an employee, a small business owner, or contractor as well as other types of work (for example, picking up scrap metal, returning carts to a grocery store for a negotiated dollar amount per cart). Outcomes were also examined for jobs that met the strict definition of "competitive employment," as defined by Bond et al.: "jobs in integrated settings (i.e., with nondisabled coworkers), paying at least minimum wage" [31, p. 491], as well as formal self-employment (defined as a Veteran-owned business in which taxes were filed based on their earnings). Work activity within the Transitional Employment Program was not included in any analysis of employment outcomes, because this was one of the VA vocational rehabilitation programs that Veterans participated in as part of the study. 
Employment outcomes can be described by total money earned, time in job (number of weeks worked at least one day), total days worked (number of actual days worked), and number of hours worked, each of which is presented in the "Results" section.

\section{RESULTS}

\section{Participant Flow}

A total of 125 Veterans expressed interest in the study, and 99 Veterans were successfully contacted. Sixty-seven Veterans were screened for the study. The other 32 Veterans were told about the study either in person or on the telephone and declined to be screened or indicated that they were not interested. Of the 67 Veterans who were screened, 26 were ineligible. Reasons for Veterans not being eligible to participate in the study included did not meet TBI criteria $(n=10)$, not interested in compensated work therapy or in being employed $(n=$ 6 ), no complaint of lasting cognitive impairment due to TBI $(n=5)$, did not meet employability criteria $(n=3)$, did not meet education criteria $(n=1)$, and involved in conflicting research $(n=1)$.

Of the 41 Veterans who were eligible, 32 Veterans completed the informed consent process. A total of seven Veterans withdrew or were withdrawn after consent but before randomization for the following reasons: did not meet cognitive impairment criteria on neuropsychological testing $(n=2)$, overwhelmed by life events $(n=2)$, successfully gained employment $(n=1)$, was no longer interested in employment $(n=1)$, and returned to Active Duty unexpectedly $(n=1)$. Twenty-five Veterans were then randomized. Six Veterans withdrew or were withdrawn after randomization and within the first two study sessions for the following reasons: mental health destabilization ( $n=3)$, unexpected move out of the area $(n=2)$, and dissatisfaction with control group assignment $(n=1)$. One participant in the control condition was later determined to be ineligible for the study due to gaining competitive employment just prior to study start, so his data were not included in the final analyses. Thus, of the remaining 18 participants, 10 were in the embedded cognitive rehabilitation intervention group and 8 were in the control group. Table 2 shows participant characteristics. All of our participants were male. The majority of participants were white, had obtained a high school diploma, and had served during the post-Vietnam war era (from
Table 2.

Participant demographics.

\begin{tabular}{|c|c|}
\hline Demographic & Participants \\
\hline$\overline{\text { Male }(n)}$ & 18 \\
\hline \multicolumn{2}{|l|}{ Age (yr) } \\
\hline Range & 25-69 \\
\hline Mean \pm SD & $51.0 \pm 8.6$ \\
\hline \multicolumn{2}{|l|}{ Ethnicity $(n)$} \\
\hline African-American/Black & 3 \\
\hline Hispanic/Latino & 4 \\
\hline White & 11 \\
\hline \multicolumn{2}{|l|}{ Education (yr) } \\
\hline Range & $10-17$ \\
\hline Mean \pm SD & $13.0 \pm 1.7$ \\
\hline \multicolumn{2}{|l|}{ Education Level $(n)$} \\
\hline High School Diploma & 15 \\
\hline Associate’s Degree & 2 \\
\hline Bachelor’s Degree & 1 \\
\hline \multicolumn{2}{|l|}{ Military Era $(n)$} \\
\hline Between Korean war and Vietnam war & 1 \\
\hline Vietnam war & 1 \\
\hline Post-Vietnam war & 14 \\
\hline Persian Gulf war & 1 \\
\hline OIF/OEF & 1 \\
\hline \multicolumn{2}{|l|}{ Mental Disorder $(n)$} \\
\hline PTSD & 8 \\
\hline MDD & 5 \\
\hline Bipolar Disorder & 3 \\
\hline OCD & 1 \\
\hline Schizoaffective Disorder & 1 \\
\hline GAD & 1 \\
\hline Other Mood or Anxiety Disorder & 7 \\
\hline \multicolumn{2}{|l|}{ Substance Use Disorder $(n)$} \\
\hline Alcohol Abuse or Dependence & 9 \\
\hline Opiate Abuse or Dependence & 2 \\
\hline Cocaine Abuse & 2 \\
\hline $\begin{array}{l}\text { GAD = generalized anxiety disorder, } \mathrm{MDD}=\text { manic } \\
\text { obsessive compulsive disorder, OIF/OEF = Operat } \\
\text { tion Enduring Freedom, PTSD = posttraumatic stre } \\
\text { deviation. }\end{array}$ & $\begin{array}{l}\text { sive disorder, OCD = } \\
\text { raqi Freedom/Opera- } \\
\text { order, } \mathrm{SD}=\text { standard }\end{array}$ \\
\hline
\end{tabular}

1975 to 1990). All study participants had been diagnosed with at least one psychiatric disorder, and a slight majority of participants had at least one substance use disorder diagnosis.

\section{Intervention Modifications}

During the first half of the study, specific challenges identified by Veterans with mTBI and MI were related to navigating the program and remembering passwords. At the halfway point in the recruitment phase, after 10 of the 
final 18 participants had been randomized (7 of the final 10 in the embedded cognitive rehabilitation intervention group and 3 of the final 8 in the control group), the entire study team met to discuss these issues and, where appropriate, respond to these challenges.

First, although participants enjoyed answering the essay questions, they were frustrated by the limited word count and the lack of feedback regarding available space to write. In response to these comments, we extended the character limit in these exercises because Veterans wanted to type longer entries, added text explanations to the screen clarifying the number of characters allowed, and added active counters indicating the number of characters left. Second, some Veterans had difficulty navigating the lessons because of changes in navigation formatting from module to module. In response to this comment, we moved all buttons from vertical to horizontal alignment to create uniformity across exercises and revised the format of listed exercises for greater clarity. Given that these changes to the intervention were minor, and 70 percent of those in the intervention group completed the original form of the intervention, we did not run analyses separately between the pre- and postmodification participants.

\section{Participation in Compensated Work Therapy Program}

There was no significant difference between the number of Veterans in the intervention and control groups who participated in vocational rehabilitation $\left(\chi^{2}=\right.$ $4.50, p=0.11)$.

\section{Participation in Intervention and Control Sessions}

Of the 10 Veterans randomly assigned to the embedded cognitive rehabilitation intervention, 70 percent attended 12 sessions and 30 percent attended 6 to 8 sessions. The number of sessions attended by the individuals in the intervention group was $10.0 \pm 2.3$ (mean \pm SD), with a range of 6 to 12 sessions. Of the eight Veterans assigned to the control condition, 15 percent attended 10 to 12 sessions, 50 percent attended 6 to 9 sessions, and 35 percent attended 3 to 5 sessions. The number of sessions attended by the individuals in the control group was $7.0 \pm 3.1$, with a range of 3 to 12 sessions.

\section{Use of Laptop Computers}

Veterans in the embedded cognitive rehabilitation intervention group used the laptop computers for more total time (717 $\pm 423 \mathrm{~min}$, with a range of 0 to $1,210 \mathrm{~min}$ ) than the control group (258 $\pm 381 \mathrm{~min}$, with a range of 0 to $950 \mathrm{~min}$ ).

\section{Qualitative Analysis: Satisfaction with Enhanced Vocational Rehabilitation Program}

All 10 Veterans assigned to the embedded cognitive rehabilitation intervention completed the satisfaction survey. In response to a question about the overall program, the majority of Veterans reported being very satisfied $(n=8)$, felt the program met their expectations $(n=8)$, and would recommend it to other Veterans $(n=9)$. The predominantly positive response was supported by the qualitative feedback. Specifically, participants commented on the helpfulness of the lessons on goal setting, managing emotions, and learning organizational and attentional skills. Participants referred to their satisfaction learning specific strategies such as setting personal direction, rethinking initial interpretations of situations, and keeping a calendar. On the other hand, negative feedback included finding some of the information covered by the curriculum irrelevant (not individualized enough), while personally relevant needs, such as help with motivation and planning, were not addressed.

Regarding the meetings with the trained neuropsychology staff member, the majority of Veterans found the meetings helpful $(n=9)$ and felt that they learned from these meetings $(n=9)$ ). Qualitatively, one Veteran stated that he appreciated completing homework assignments and receiving feedback on his work. Another Veteran felt that the sessions allowed him to learn skills collaboratively that would help him achieve success.

Regarding the ISI software, the majority of Veterans reported it was easy to use $(n=6)$ and helpful for reaching their work goals $(n=8)$. Qualitatively, one participant noted that completing the computer-based assignments improved his computer skills, which he anticipated as a necessary skill for future employment. On the other hand, other Veterans commented that technical difficulties, such as the computer crashing or not understanding how to follow the software instructions or how to save assignments, created frustration.

\section{Preliminary Analyses}

Preliminary analyses found no significant differences between the intervention and control groups at baseline on age, education, or relationship status. In regards to unemployment history, there were no significant differences between the intervention and control groups in 
weeks of competitive employment the previous year $(t(16)=1.26, p=0.23)$. The control and intervention groups were administered neuropsychological testing during eligibility screening, and analyses revealed no differences between the two groups. There were also no significant differences between groups on self-report measures of anxiety and depression.

\section{Quantitative Analysis: Employment Outcomes}

As stated in the "Methods" section, it is important to reiterate that the results were not statistically significant since this pilot study was not powered to detect statistical significance, because the total $N$ was only 18 ( $n=10$ for the intervention group and $n=8$ for the control group) (Table 3).

Overall, twice the percentage of Veterans in the embedded cognitive rehabilitation intervention group attained competitive employment (50\%) than did control group Veterans (25\%) $\left(\chi^{2}=1.17, p=0.28, d=0.26\right)$. At month 4 , the embedded cognitive rehabilitation intervention group had higher rates of competitive employment $\left(\chi^{2}=0.18, p=0.67, d=0.10\right)$. By month 12 , competitive employment rates were 50 percent for the embedded cognitive rehabilitation intervention group compared with 12.5 percent for the control group $\left(\chi^{2}=2.81, p=0.09\right.$, $d=0.40$ ).

Considering the total sample $(N=18)$, embedded cognitive rehabilitation intervention and control partici- pants worked roughly the same number of weeks (20.80 vs 19.88 wk; Mann-Whitney $z=-0.732, p=0.46, d=$ 0.17), but the embedded cognitive rehabilitation intervention participants worked more than twice as many total days (67.90 vs $28.00 \mathrm{~d}$; Mann-Whitney $z=-1.190, p=$ $0.23, d=0.28)$ and almost three times as many hours as control participants (481.60 vs $160.88 \mathrm{~h}$; Mann-Whitney $z=-1.373, p=0.17, d=0.32)$. Still considering the total sample $(N=18)$, earnings over the following year period averaged \$5,193.47 more for the embedded cognitive rehabilitation intervention group (\$6,825.10 $\pm \$ 8,627.52)$ than the control group $(\$ 1,631.63 \pm \$ 3,123.23$; MannWhitney $z=-1.282, p=0.20, d=0.30)$.

Considering only Veterans who earned pay for any kind of work outside of TWE (competitive employment, day labor, or formal or informal self-employment) during the study period, embedded cognitive rehabilitation intervention and control participants worked roughly the same number of weeks (29.71 vs 31.80 wk; Mann-Whitney $z=$ $-0.568, p=0.57, d=0.16$ ), but embedded cognitive rehabilitation intervention participants worked more than twice as many days ( 97.00 vs $44.80 \mathrm{~d}$; Mann-Whitney $z=$ $-1.380, p=0.17, d=0.40)$ and hours (688.00 vs $257.40 \mathrm{~h}$; Mann-Whitney $z=-1.705, p=0.09, d=0.49$ ) than control participants. Earnings over the year period were more than three times as much for intervention

Table 3.

Employment outcomes by condition.

\begin{tabular}{|c|c|c|c|c|c|}
\hline Outcome & $\begin{array}{c}\text { Intervention Group } \\
\text { (mean } \pm \text { SD) }\end{array}$ & $\begin{array}{l}\text { Control Group } \\
\text { (mean } \pm \text { SD) }\end{array}$ & $Z$ & $p$-Value & $d$ \\
\hline \multicolumn{6}{|c|}{ All Participants (I = 10, C = 8) } \\
\hline Weeks & $20.80 \pm 18.52$ & $19.88 \pm 32.60$ & -0.732 & 0.46 & 0.17 \\
\hline Days & $67.90 \pm 78.22$ & $28.00 \pm 37.81$ & -1.190 & 0.23 & 0.28 \\
\hline Hours & $481.60 \pm 613.81$ & $160.88 \pm 280.57$ & -1.373 & 0.17 & 0.32 \\
\hline Earnings & $\$ 6,825.10 \pm \$ 8,627.52$ & $\$ 1,631.63 \pm \$ 3,123.23$ & -1.282 & 0.20 & 0.30 \\
\hline \multicolumn{6}{|c|}{ Only Participants Who Worked During Study ${ }^{*}(\mathrm{I}=7, \mathrm{C}=5)$} \\
\hline Weeks & $29.71 \pm 14.33$ & $31.80 \pm 37.23$ & -0.568 & 0.57 & 0.16 \\
\hline Days & $97.00 \pm 76.72$ & $44.80 \pm 39.51$ & -1.380 & 0.17 & 0.40 \\
\hline Hours & $688.00 \pm 632.04$ & $257.40 \pm 326.65$ & -1.705 & 0.09 & 0.49 \\
\hline Earnings & $\$ 9,750.14 \pm \$ 8,853.15$ & $\$ 2,610.60 \pm \$ 3,725.03$ & -1.543 & 0.12 & 0.46 \\
\hline \multicolumn{6}{|c|}{ Only Participants Who Worked in Competitive Employment During Study $(I=5, C=2)$} \\
\hline Weeks & $28.00 \pm 15.95$ & $61.50 \pm 48.79$ & -0.775 & 0.44 & 0.29 \\
\hline Days & $102.40 \pm 90.75$ & $65.00 \pm 57.98$ & -0.387 & 0.70 & 0.15 \\
\hline Hours & $805.40 \pm 723.30$ & $460.50 \pm 515.48$ & -0.775 & 0.44 & 0.29 \\
\hline Earnings & $\$ 10,311.80 \pm \$ 10,777.88$ & $\$ 5,292.00 \pm \$ 5,519.68$ & -0.387 & 0.70 & 0.15 \\
\hline
\end{tabular}


participants, an average of $\$ 7,139.54$ more, than for control participants (Mann-Whitney $z=-1.543, p=0.12$, $d=0.46)$.

Considering only those participants who obtained competitive employment or began their own businesses (formal self-employment; paying taxes on income earned, etc.; not day labor or informal self-employment), control participants worked more weeks total than intervention participants (61.50 vs 28.00 wk; Mann-Whitney $z=-0.775, p=0.44, d=0.29$ ). However, intervention participants worked more days $(102.40$ vs $65.00 \mathrm{~d}$; Mann-Whitney $z=-0.387, p=0.70, d=0.15$ ) and hours (805.40 vs $460.50 \mathrm{~h}$; Mann-Whitney $z=-0.775, p=0.44$, $d=0.29$ ) of competitive employment over the $1 \mathrm{yr}$ period than control participants. Earnings over the year period were almost twice as much for intervention participants, an average of $\$ 5,019.80$ more, than for control participants (Mann-Whitney $z=-0.387, p=0.70, d=0.15$ ).

\section{DISCUSSION}

The goal of this pilot study was to develop and test the feasibility and potential efficacy of adding an embedded cognitive rehabilitation intervention to standard vocational rehabilitation in Veterans with histories of MTBI and MI. We postulated that the incorporation of the embedded cognitive rehabilitation intervention has the potential to improve employment outcomes above and beyond standard vocational rehabilitation services alone. When considering our outcomes, it is important to keep in mind that complex functional outcomes, such as employment, are influenced by multiple factors and not just cognitive variables. Our intention was to focus on the cognitive variables that may impede successful return to work.

To accomplish this, a total of 125 Veterans were contacted initially, and 67 expressed interest in continuing to the screening process. Of the 47 percent who did not agree to be screened, it is unknown whether it was because of lack of interest or that they judged they would not be eligible (did not meet TBI criteria, etc.). Of the 67 Veterans who did complete the screening, 19 (28\%) did not meet criteria for the target population (unemployed or underemployed with history of TBI and current cognitive impairment).

Given the literature about the effect of cognitive impairment on employment for individuals with a range of mental health diagnoses (with or without TBI), the recruitment findings suggest expanding the target population to include all those with cognitive impairment due to any cause other than dementia, stroke, etc. [20]. It is notable that 7 Veterans (10\%) were not interested in employment or vocational services, which may suggest that even if services were offered, there would be a significant minority who would not participate because of lack of interest in employment. For these individuals, other services would need to be offered. Given that 4 Veterans (6\%) did not meet employability or educational criteria, it would be important in a larger study to look at the effect of lower levels of employment history and education on outcomes to understand for which populations the program is most likely to be useful.

Of the 18 participants enrolled in the program, 10 were in the 12 session embedded cognitive rehabilitation intervention where they were taught compensatory strategies to help manage cognitive, behavioral, emotional, and interpersonal difficulties in the occupational environment and 8 were in the control group receiving 12 sessions of supportive client-centered therapy that did not focus on employment or cognitive rehabilitation. Veterans in the embedded cognitive rehabilitation intervention had higher participation rates (70\% attended 12 sessions) than those in the control group (15\% attended 10-12 sessions), suggesting that the control group was not as attractive as the intervention group. Thus, in future studies, additional aspects should be added to the control group to increase acceptability and better control for attention and possibly resentful demoralization. Future studies in this area should formally assess satisfaction and acceptability of both conditions, not just the intervention.

\section{Summary of Qualitative Findings and Implications}

This pilot project demonstrated the ability to successfully implement an embedded cognitive rehabilitation intervention for Veterans with MTBI and MI within vocational rehabilitation to help Veterans return to work. Importantly, Veterans felt that the least helpful computerbased modules were those that strictly taught them jobspecific skills, such as customer service skills. This suggests that skills training for a specific job (which may not match their interests or preferences) is not particularly valued by Veterans in vocational rehabilitation. Qualitative information on the effectiveness of the program was positive. Veterans reported that they found lessons on goal setting, managing emotions, and learning organizational and attentional skills helpful, including learning specific 
strategies such as setting personal directions, rethinking initial interpretations of situations, and learning how to use a calendar. Regarding ISI software content, Veterans felt that many of the modules were helpful in assisting them reach their work goals. The most helpful modules were those that focused on motivational and relational issues that might be affecting return to work. Veterans appreciated working collaboratively, one-on-one with trained neuropsychology staff and/or trainees to complete homework and receive feedback on homework that included trouble-shooting to better assist with generalization of skills to daily life outside the office.

\section{Summary of Quantitative Findings and Implications}

Although the statistical power was not intended to investigate statistically significant results in this small pilot, useful preliminary information can be gleaned from the quantitative information gathered. By the 12 mo follow-up, competitive employment rates were higher for the embedded cognitive rehabilitation intervention group (50\%) than for the control group (12.5\%). An exploration of employment outcomes over the 12 mo demonstrated small to moderate effect sizes (Cohen $d=0.28-0.49$ ) favoring the embedded cognitive rehabilitation intervention group on certain employment outcomes, including days worked, hours worked, and money earned. The results from this pilot study can be used to inform future hypotheses on the effectiveness of cognitive rehabilitation and may provide some evidence on whether a larger sample will likely yield statistically significant differences.

Previous nonrandomized studies have demonstrated promising results in including cognitive rehabilitation in traditional vocational rehabilitation for civilians with TBI [22,43-44]. In a recent study focused on OIF/OEF Veterans with mTBI to moderate TBI, incorporation of cognitive rehabilitation services and SE was found to be beneficial in reducing mental health symptoms, improving self-report of postconcussive symptoms, and boosting attainment of competitive employment [45]. Our study adds to this body of literature by demonstrating the feasibility of embedding a cognitive rehabilitation program within VA vocational rehabilitation services. Our results provide additional evidence that offering cognitive rehabilitation along with vocational rehabilitation for cognitively impaired Veterans with TBI and MI may improve return to work [45]. This small body of literature underscores the importance of using cognitive rehabilitation services to create changes in functional aspects (e.g., employment) of Veteran's daily lives, consistent with the goals of vocational rehabilitation, which support the belief that anyone, regardless of disability, is employable when provided with the right resources [52].

\section{Limitations}

Limitations of the current study include our small sample size, which did not permit for fully powered statistical analysis. First, we analyzed only the participants who did not withdraw from the study, not using an intentto-treat approach. For a larger powered clinical trial, it will be important to include all randomized participants in the analysis. Second, we made some adjustments to the embedded cognitive rehabilitation intervention after the study started, and it is unclear how these adjustments affected the overall results. Our sample also consisted entirely of male Veterans. Given the increases in female servicemembers and the potentially unique needs of female Veterans, it will be critical to determine whether approaches like the one described here can be similarly applied to women. In addition, our Veterans were mostly Caucasian and had obtained a high school diploma. Given the significant diversity in the Veteran population, more research will have to be done to evaluate whether these preliminary results would apply to broader Veteran samples. Third, there were significant challenges to using computer-based software, including frustrations related to navigation that required restructuring of the elements on the screen. There was also a learning curve for Veterans with less computer experience that may have decreased the efficacy of the intervention itself, given that time was needed to teach basic computer literacy. However, at least one Veteran remarked that using the computer was helpful in improving his computer skills, and this may be advantageous in certain employment environments. The variability in participation level (greater attendance in the intervention group than in the control group) may also have affected the study outcome in favor of the intervention group. At least one Veteran described feeling as if a more tailored, individualized intervention would be more helpful given the irrelevance of certain aspects of the manualized treatment. Future studies should examine the benefits of tailored versus manualized cognitive rehabilitation therapies. Fourth, it is important to acknowledge that a greater proportion of participants in the intervention group were seen by doctoral-level staff than participants in the control condition, who were seen largely by master's level staff or trainees. 
It is possible that the level of training and/or clinician expertise influenced the outcomes. Last, qualitative information gathered for this study was based on selfreport. Future studies could include collateral information from family members or other healthcare providers or objective cognitive tests to further assess the range of outcomes.

\section{CONCLUSIONS}

This pilot study focused on the development and feasibility of an embedded cognitive rehabilitation intervention using ISI software with a vocational program. As described in the present article, employment outcomes were positive and the program demonstrated efficient implementation in a VA setting. Given these preliminary findings, a larger outcome study is now warranted in order to determine the efficacy of the intervention in improving competitive employment outcomes as well as cognitive functioning and functional abilities in the workplace.

\section{ACKNOWLEDGMENTS}

\section{Author Contributions:}

Study design: M. K. O’Connor, L. Mueller, C. E. Drebing. Acquisition of data: A. A. O’Connor, A. Semiatin, S. Wang. Interpretation of data: M. K. O’Connor, L. Mueller, E. Kwon, S. Wang.

Drafting of manuscript: M. K. O’Connor, L. Mueller, E. Kwon, R. Daley.

Financial Disclosures: The authors gratefully acknowledge the contribution of ISI for their financial support for this project.

Funding/Support: This material was based on work supported by ISI, who donated seven laptop computers, software, and technical assistance.

Additional Contributions: We also thank Rodney Cleaves and Steven Milligan from the Bedford VA Medical Center Information Resource Management Service for their assistance with encrypting the laptop computers and preparing them for Veteran use. Dr. Semiatin is now with the Department of Psychology, Manchester VA Medical Center, Manchester, New Hampshire. Ms. O’Connor is now with the University of Denver, Denver, Colorado, and the Iowa City VA Health Care System, Iowa City, Iowa.

Institutional Review: All of the participants who contributed to the study signed informed consent forms approved by the Bedford VA Medical Center Institutional Review Board.

Participant Follow-up: The authors do not plan to inform participants for the publication of this study because of a lack of contact information.

\section{REFERENCES}

1. Binder LM, Rohling ML, Larrabee GJ. A review of mild head trauma. Part I: Meta-analytic review of neuropsychological studies. J Clin Exp Neuropsychol. 1997;19(3):421-31. [PMID:9268816] http://dx.doi.org/10.1080/01688639708403870

2. Levin HS, Eisenberg HM, Benton AL. Mild head injury. New York (NY): Oxford University Press; 1989.

3. Mathias JL, Beall JA, Bigler ED. Neuropsychological and information processing deficits following mild traumatic brain injury. J Int Neuropsychol Soc. 2004;10(2):286-97. [PMID:15012849] http://dx.doi.org/10.1017/S1355617704102117

4. Alexander MP. Mild traumatic brain injury: Pathophysiology, natural history, and clinical management. Neurology. 1995;45(7):1253-60. [PMID:7617178] http://dx.doi.org/10.1212/WNL.45.7.1253

5. Dikmen S, Machamer J, Fann JR, Temkin NR. Rates of symptom reporting following traumatic brain injury. J Int Neuropsychol Soc. 2010;16(3):401-11. [PMID:20188017] http://dx.doi.org/10.1017/S1355617710000196

6. Kushner D. Mild traumatic brain injury: Toward understanding manifestations and treatment. Arch Intern Med. 1998;158(15):1617-24. [PMID:9701095] http://dx.doi.org/10.1001/archinte.158.15.1617

7. Ponsford J, Willmott C, Rothwell A, Cameron P, Kelly AM, Nelms R, Curran C, Ng K. Factors influencing outcome following mild traumatic brain injury in adults. J Int Neuropsychol Soc. 2000;6(5):568-79. [PMID:10932476] http://dx.doi.org/10.1017/S1355617700655066

8. Brenner LA, Ivins BJ, Schwab K, Warden D, Nelson LA, Jaffee M, Terrio H. Traumatic brain injury, posttraumatic stress disorder, and postconcussive symptom reporting among troops returning from Iraq. J Head Trauma Rehabil. 2010;25(5):307-12. [PMID:20042982] http://dx.doi.org/10.1097/HTR.0b013e3181cada03

9. Hoge CW, McGurk D, Thomas JL, Cox AL, Engel CC, Castro CA. Mild traumatic brain injury in U.S. Soldiers returning from Iraq. N Engl J Med. 2008;358(5):453-63. [PMID:18234750] http://dx.doi.org/10.1056/NEJMoa072972

10. Tanielian TL, Jaycox LH, editors. Invisible wounds of war: Psychological and cognitive injuries, their consequences, and services to assist recovery. Santa Monica (CA): RAND Center for Military Health Policy Research; 2008.

11. Terrio H, Brenner LA, Ivins BJ, Cho JM, Helmick K, Schwab K, Scally K, Bretthauer R, Warden D. Traumatic brain injury screening: Preliminary findings in a US Army Brigade Combat Team. J Head Trauma Rehabil. 2009; 24(1):14-23. [PMID:19158592] http://dx.doi.org/10.1097/HTR.0b013e31819581d8 
12. Belanger HG, Uomoto JM, Vanderploeg RD. The Veterans Health Administration's (VHA's) Polytrauma System of Care for mild traumatic brain injury: Costs, benefits, and controversies. J Head Trauma Rehabil. 2009;24(1):4-13. [PMID:19158591] http://dx.doi.org/10.1097/HTR.0b013e3181957032

13. Spencer RJ, Drag LL, Walker SJ, Bieliauskas LA. Selfreported cognitive symptoms following mild traumatic brain injury are poorly associated with neuropsychological performance in OIF/OEF veterans. J Rehabil Res Dev. 2010; 47(6):521-30. [PMID:20848365]

http://dx.doi.org/10.1682/JRRD.2009.11.0181

14. Jorge RE, Robinson RG, Moser D, Tateno A, CrespoFacorro B, Arndt S. Major depression following traumatic brain injury. Arch Gen Psychiatry. 2004;61(1):42-50.

[PMID:14706943]

http://dx.doi.org/10.1001/archpsyc.61.1.42

15. Meares S, Shores EA, Batchelor J, Baguley IJ, Chapman J, Gurka J, Marosszeky JE. The relationship of psychological and cognitive factors and opioids in the development of the postconcussion syndrome in general trauma patients with mild traumatic brain injury. J Int Neuropsychol Soc. 2006; 12(6):792-801. [PMID:17064443]

16. Moore EL, Terryberry-Spohr L, Hope DA. Mild traumatic brain injury and anxiety sequelae: A review of the literature. Brain Inj. 2006;20(2):117-32. [PMID:16421060] http://dx.doi.org/10.1080/02699050500443558

17. Rapoport MJ, McCullagh S, Streiner D, Feinstein A. The clinical significance of major depression following mild traumatic brain injury. Psychosomatics. 2003;44(1):31-37. [PMID:12515835] http://dx.doi.org/10.1176/appi.psy.44.1.31

18. Silver JM, McAllister TW, Arciniegas DB. Depression and cognitive complaints following mild traumatic brain injury. Am J Psychiatry. 2009;166(6):653-61. [PMID:19487401] http://dx.doi.org/10.1176/appi.ajp.2009.08111676

19. Donnell AJ, Kim MS, Silva MA, Vanderploeg RD. Incidence of postconcussion symptoms in psychiatric diagnostic groups, mild traumatic brain injury, and comorbid conditions. Clin Neuropsychol. 2012;26(7):1092-1101.

[PMID:22935025] http://dx.doi.org/10.1080/13854046.2012.713984

20. O’Connor MK, Mueller L, Van Ormer A, Drake R, Penk W, Rosenheck R, Semiatin A, Drebing CE. Cognitive impairment as barrier to engagement in vocational services among veterans with severe mental illness. J Rehabil Res Dev. 2011;48(5):597-608. [PMID:21674409]

http://dx.doi.org/10.1682/JRRD.2010.06.0117

21. Drebing CE, Mueller L, Van Ormer EA, Duffy P, LePage J, Rosenheck R, Drake R, Rose GS, King K, Penk W. Pathways to vocational services: Factors affecting entry by veterans enrolled in Veterans Health Administration mental health services. Psychol Serv. 2012;9(1):49-63.

\section{[PMID:22449087]}

http://dx.doi.org/10.1037/a0026662

22. McGurk SR, Mueser KT, Feldman K, Wolfe R, Pascaris A. Cognitive training for supported employment: 2-3 year outcomes of a randomized controlled trial. Am J Psychiatry. 2007;164(3):437-41. [PMID:17329468]

http://dx.doi.org/10.1176/ajp.2007.164.3.437

23. Bond GR. Supported employment: Evidence for an evidencebased practice. Psychiatr Rehabil J. 2004;27(4):345-59.

[PMID:15222147]

http://dx.doi.org/10.2975/27.2004.345.359

24. McGurk SR, Meltzer HY. The role of cognition in vocational functioning in schizophrenia. Schizophr Res. 2000; 45(3):175-84. [PMID:11042435]

http://dx.doi.org/10.1016/S0920-9964(99)00198-X

25. O’Neill J, Hibbard MR, Brown M, Jaffe M, Sliwinski M, Vandergroot D, Weiss MJ. The effect of employment on quality of life and community integration after traumatic brain injury. J Head Trauma Rehabil. 1998;13(4):68-79.

[PMID:9651241]

http://dx.doi.org/10.1097/00001199-199808000-00007

26. Melamed S, Groswasser Z, Stern MJ. Acceptance of disability, work involvement and subjective rehabilitation status of traumatic brain-injured (TBI) patients. Brain Inj. 1992;6(3):233-43. [PMID:1533808]

http://dx.doi.org/10.3109/02699059209029665

27. Bond GR, Becker DR, Drake RE, Rapp CA, Meisler N, Lehman AF, Bell MD, Blyler CR. Implementing supported employment as an evidence-based practice. Psychiatr Serv. 2001;52(3):313-22. [PMID:11239097]

http://dx.doi.org/10.1176/appi.ps.52.3.313

28. Mueser KT, Becker DR, Torrey WC, Xie H, Bond GR, Drake RE, Dain BJ. Work and nonvocational domains of functioning in persons with severe mental illness: A longitudinal analysis. J Nerv Ment Dis. 1997;185(7):419-26. [PMID:9240359]

http://dx.doi.org/10.1097/00005053-199707000-00001

29. Wehman P, Targett P, West M, Kregel J. Productive work and employment for persons with traumatic brain injury: What have we learned after 20 years? J Head Trauma Rehabil. 2005;20(2):115-27. [PMID:15803036] http://dx.doi.org/10.1097/00001199-200503000-00001

30. Partridge TM. An investigation into the vocational rehabilitation practices provided by brain injury services throughout the United Kingdom. Work. 1996;7(1):63-72. [PMID:24441622] http://dx.doi.org/10.1016/1051-9815(96)00188-X

31. Bond GR, Resnick SG, Drake RE, Xie H, McHugo GJ, Bebout RR. Does competitive employment improve nonvocational outcomes for people with severe mental illness? J Consult Clin Psychol. 2001;69(3):489-501.

[PMID:11495178] http://dx.doi.org/10.1037/0022-006X.69.3.489 
32. Steadman-Pare D, Colantonio A, Ratcliff G, Chase S, Vernich L. Factors associated with perceived quality of life many years after traumatic brain injury. J Head Trauma Rehabil. 2001;16(4):330-42. [PMID:11461656] http://dx.doi.org/10.1097/00001199-200108000-00004

33. Fabian ES. Supported employment and the quality of life: Does a job make a difference? Rehabil Couns Bull. 1992; 36(2):84-97.

34. Rubin SE, Roessler RT. Foundations of the vocational rehabilitation process. 5th ed. Austin (TX): Pro-Ed; 2001.

35. Becker DR, Drake RE. A working life for people with severe mental illness. New York (NY): Oxford University Press; 2003.

36. Bond GR. Principles of the individual placement and support model: Empirical support. Psychiatr Rehabil J. 1998; 22(1):11-23. http://dx.doi.org/10.1037/h0095271

37. Wehman P. Supported competitive employment for persons with severe disabilities. J Appl Rehabil Counsel. 1986; 17:24-29.

38. Losardo ML. Veterans in need of services: The history and development of the Edith Nourse Rogers Memorial VA Hospital Compensated Work Therapy Program. Boston (MA): University of Massachusetts; 1999.

39. McGurk SR, Mueser KT, Pascaris A. Cognitive training and supported employment for persons with severe mental illness: One-year results from a randomized controlled trial. Schizophr Bull. 2005;31(4):898-909. [PMID:16079391] http://dx.doi.org/10.1093/schbul/sbi037

40. Crépeau F, Scherzer P. Predictors and indicators of work status after traumatic brain injury: A meta-analysis. Neuropsychol Rehabil. 1993;3(1):5-35.

http://dx.doi.org/10.1080/09602019308401421

41. Ezrachi O, Ben-Yishay Y, Kay T, Diller L, Rattok J. Predicting employment in traumatic brain injury following neuropsychological rehabilitation. J Head Trauma Rehabil. 1991;6(3):71-84. http://dx.doi.org/10.1097/00001199-199109000-00010

42. Sherer M, Novack TA, Sander AM, Struchen MA, Alderson A, Thompson RN. Neuropsychological assessment and employment outcomes after traumatic brain injury: A review. Clin Neuropsychol. 2002;16(2):157-78. http://dx.doi.org/10.1076/clin.16.2.157.13238

43. O’Neill JH, Zuger RR, Filed A, Fraser R, Pruce T. The Program Without Walls: Innovative approach to state agency vocational rehabilitation of persons with traumatic brain injury. Arch Phys Med Rehabil. 2004;85(4 Suppl 2):S68-72. [PMID:15083424]

44. Sarajuuri JM, Kaipio ML, Koskinen SK, Niemelä MR, Servo AR, Vilkki JS. Outcome of a comprehensive neurorehabilitation program for patients with traumatic brain injury. Arch Phys Med Rehabil. 2005;86(12):2296-2302. [PMID:16344026] http://dx.doi.org/10.1016/j.apmr.2005.06.018
45. Twamley EW, Jak AJ, Delis DC, Bondi MW, Lohr JB. Cognitive Symptom Management and Rehabilitation Therapy (CogSMART) for veterans with traumatic brain injury: Pilot randomized controlled trial. J Rehabil Res Dev. 2014; 51(1):59-70. [PMID:24805894] http://dx.doi.org/10.1682/JRRD.2013.01.0020

46. Drake RE, McHugo GJ, Becker DR, Anthony WA, Clark RE. The New Hampshire study of supported employment for people with severe mental illness. J Consult Clin Psychol. 1996;64(2):391-99. [PMID:8871423] http://dx.doi.org/10.1037/0022-006X.64.2.391

47. Vollrath M, Alnaes R, Torgersen S. Coping and MCMI-II symptom scales. J Clin Psychol. 1994;50(5):727-36. [PMID:7806650]

48. Blankertz L, Robinson S. Adding a vocational focus to mental health rehabilitation. Psychiatr Serv. 1996;47(11): 1216-22. [PMID:8916239] http://dx.doi.org/10.1176/ps.47.11.1216

49. Mowbray CT, Rusilowski-Clover G, Arnold J, Allen C, Harris S, McCrohan N, Greenfield A. Project WINS: Integrating vocational services on mental health case management teams. Community Ment Health J. 1994;30(4):347-62. [PMID:7956111] http://dx.doi.org/10.1007/BF02207488

50. Kay T, Harrington DE, Adams R, Anderson T, Berrol S, Cicerone K, Dahlberg C, Gerber D, Goka R, Harley P, Hilt J, Horn L, Lehmkuhl D, Malec J. Definition of mild traumatic brain injury. J Head Trauma Rehabil. 1993;8(3):86-87.

51. Folstein MF. MMSE: Mini-Mental State Examination: User's guide. Odessa (TX): PAR; 2001.

52. Wehman P, Gentry T, West M, Arango-Lasprilla JC. Community integration: Current issues in cognitive and vocational rehabilitation for individuals with ABI. J Rehabil Res Dev. 2009;46(6):909-18. [PMID:20104411] http://dx.doi.org/10.1682/JRRD.2008.08.0105

Submitted for publication October 9, 2014. Accepted in revised form August 12, 2015.

This article and any supplementary material should be cited as follows:

O’Connor MK, Mueller L, Kwon E, Drebing CE, O’Connor AA, Semiatin A, Wang S, Daley R. Enhanced vocational rehabilitation for Veterans with mild traumatic brain injury and mental illness: Pilot study. J Rehabil Res Dev. 2016;53(3):307-20.

http://dx.doi.org/10.1682/JRRD.2014.10.0231

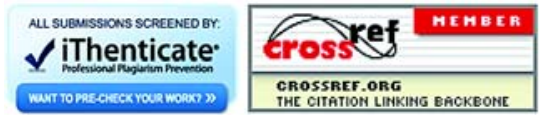


